\title{
Os Jovens e o Pentecostalismo: Considerações sobre a identidade da juventude da igreja Assembleia de Deus a partir um estudo de caso na Baixada Fluminense -RJ
}

Alexander Soares Magalhães*

\section{Resumo}

Este artigo pretende apresentar algumas considerações acerca da juventude da igreja Assembleia de Deus a partir do que se propõe chamar de "identidade juvenil assembleiana". Tal identidade invoca uma simbologia pentecostal "clássica" e, remontando à trajetória da centenária igreja brasileira Assembleia de Deus, se caracteriza pela observância (negociada) aos chamados usos e costumes -visíveis nas vestimentas e hábitos do cotidiano - e por uma resistência aos valores tidos como "do mundo", categoria nativa construída a partir da oposição ao "que é de Deus". Ao incentivar o jovem a estabelecer suas diversas formas de sociabilidade entre aqueles que operam nesse código cultural de "separação do mundo", essa identidade se afirma como um tipo de resistência às chamadas identidades "pós-modernas", marcadas pela fluidez e multiplicidade. Entretanto, ela se diferencia do que se pode chamar de uma "identidade assembleiana", ao dialogar com as especificidades típicas da condição juvenil das camadas populares brasileiras, tentando lidar com as dificuldades e dilemas típicos desse grupo, mas sem deixar de marcar sua identidade própria, de acordo com os preceitos da igreja supracitada.

\section{Palavras-chave}

Assembleia de Deus. Juventude. Identidade.

\section{Abstract}

This article intends to make a few considerations regarding the Assemblies of God's youth from a proposal of a specific form of identification known as "assembly youth identity". This conceptualization invokes a "classic" Pentecostal symbology, rebuilding the church's centenary trajectory, reaffirming itself as a type of resistance against the so-called postmodern

* Alexander Soares é professor de ensino básico, técnico e tecnológico do Centro Federal de Educação Tecnológica Celso Suckow da Fonseca (CEFET-RJ). E-mail: alexird@yahoo.com.br. 
identities, marked by fluidity and multiplicity. This identity is visible because of two main characteristics: the (negotiated) observance of what is known as practices and customs which come from a theological tradition but are more visible in their clothes and daily customs - as well as the resistance to values seen as "worldly", which is a category created from an opposition of what is "Godly". This identity encourages young people to establish their many ways of sociability among those who operate in the shared cultural code of "separation from the world". However, it is different from the what is known as "assembly identity", because they intend to dialog with the typical specificities of the youth condition in Brazilian popular layers, trying to deal with the hardships and dilemmas typical of this group, but still stating their own identity, according to the precepts of the aforementioned church.

\section{Keywords}

Assemblies of God. Youth. Identity.

\section{Introdução}

No campo religioso, um dos problemas mais discutidos na contemporaneidade é o processo de transformações pelo qual passam as religiosidades, no qual as estruturas e instituições religiosas experimentam grande mudança. Segundo a socióloga francesa Danièle Hervieu-Léger, no quadro atual (principalmente da Europa) de erosão da transmissão religiosa, a identidade religiosa não é mais uma identidade herdada, mas uma construção individual "a partir dos diversos recursos simbólicos colocados à sua disposição" (HERVIEU-LÉGER, 2008). Desta forma, para a autora, não se perde a relação da identidade com a religião, mas ela é ressignificada a partir das elaborações e estratégias individuais de crença e pertencimento. Assim, nesse contexto, a identidade religiosa se individualiza e é recriada a partir da bricolagem de crenças, reconfigurando as formas de pertencimento religioso.

Por sua vez, na teoria social contemporânea, o processo de transformações pelo qual passam as identidades culturais, também faz-se sentir em várias esferas da vida social, especialmente no âmbito das relações de poder, em que a política de identidade de classe passa a dividir cada vez mais espaço com a política da diferença (HALL, 2011). Ao colocar as duas questões em interseção, o panorama não é muito distinto, com muitas transformações no quadro das identidades religiosas.

Atualmente, tais transformações parecem afetar especialmente os 
jovens de camadas médias urbanas, algumas vezes tomando a direção da bricolagem e ressignificação individualizada. Segundo Novaes (2005), são encontradas algumas tendências: primeiramente, uma forte disposição para o trânsito religioso e novas combinações sincréticas, em que a prática da fé não obedece completamente aos preceitos e dogmas que determinada religião defende/impõe, e elementos de religiosidades distintas são recombinados a partir de uma demanda ou prática específica. Em segundo lugar, registra-se o aumento de escolhas e sínteses individuais, em que os vínculos formais perdem um pouco de importância. Desta forma, uma parte mais significativa dos jovens brasileiros vem valorizando mais a fé por si só do que às igrejas e instituições religiosas. Em terceiro lugar, a transferência religiosa intergeracional ocorre de forma menos regular quando comparada com outras gerações, uma vez que é mais comum a escolha de uma determinada religião ou forma de religiosidade por iniciativa própria, não por orientação familiar ou costume. E em quarto lugar, a relação de intimidade com Deus é ressignificada, sem o temor e a distância tão presentes nas gerações anteriores (NOVAES, 2005).

Entretanto, o caso que este trabalho se propõe a analisar é distinto das tendências apresentadas: será visto como a identidade juvenil assembleiana seconfigura como uma oposição a esse quadro deressignificações individuais e bricolagem de fé típicas dos modelos identitários pós-modernos. Desta forma, será defendida a tese de que existem dois elementos centrais que vão caracterizar tal marco identitário: a valorização dos chamados "usos e costumes" e a relação do jovem com o chamado "mundo". O suposto "conservadorismo" inerente a essa formação de identificação religiosa nesse contexto é um dado que se mostra relevante no complexo mercado de bens simbólicos existente no campo religioso brasileiro contemporâneo, visto que ele vai se apresentar como uma espécie de "proteção" aos ventos trazidos pela modernidade contemporânea, vinculada à satisfação dos prazeres e satisfação imediatos ligados aos padrões de consumo, panorama típico da modernidade líquida, na qual os relacionamentos em geral estão sendo tratados como mercadorias. (BAUMAN, 2003). A relevância dessa identidade dá-se quando há uma oferta palpável de segurança, estabilidade e moralidade a partir dos padrões da igreja para com os jovens, que também oferece suporte material ao auxiliar nas estratégias em como lidar com a pobreza (MARIZ, 1994) e no campo das relações interpessoais, ao oferecer um espaço material e simbólico para o florescimento de amizades (MAGALHÃES, 2016). 


\section{Estratégias metodológicas}

As informações que embasam este trabalho foram coletadas utilizando a estratégia metodológica da triangulação, combinando análise quantitativa de dados coletados por um survey com a análise qualitativa de entrevistas em profundidade e observação participante. Desta forma, as estratégias metodológicas utilizadas partem da conviçcão de que as pessoas não são simples portadoras de estruturas sociais, mas também produtoras desse social através de suas ações e também depositárias de um saber importante que deve ser interpretado e compreendido (KAUFMANN, 2013).

A pesquisa foi realizada entre 2012 e 2016, nos municípios de São João de Meriti e Duque de Caxias, região metropolitana do Rio de Janeiro. Optouse por realizar o estudo em apenas um Ministério da $\mathrm{AD}$, entre muitos existentes na região. A primeira parte da pesquisa contou com a observação participante, que consistiu basicamente de acompanhamento de cerca de 50 cultos, todos públicos: cultos de mocidade, de consagração, de missões, cultos em "Congressos" dos departamentos de adolescentes e mocidade, além de outros sem nomenclatura específica. Também foram acompanhados alguns ensaios da mocidade, sendo alguns de rotina da igreja e outros específicos para Congressos e celebrações pontuais. O segundo passo realizado para a coleta de dados foi a entrevista em profundidade. Seu objetivo principal era conhecer um pouco das histórias das amizades dos interlocutores, assim como suas concepções acerca do que pensam sobre o significado da amizade como uma relação interpessoal, e compreendê-las dentro de suas trajetórias de vida e em seus contextos de conviç̧ões e práticas religiosas. Para tal, lançou-se mão da entrevista compreensiva (KAUFMANN, 2013), na qual os interlocutores eram convidados a contar um pouco de suas vidas, a partir de um esforço do pesquisador em quebrar quaisquer tipos de barreiras hierárquicas que pudessem estar presentes durante o processo. Nessa etapa foram entrevistados dez membros com o seguinte perfil: idade entre 14 e 24 anos e participante frequente das atividades de sua igreja. As entrevistas seguiam um roteiro prévio, mas eram conduzidas de forma que o interlocutor pudesse falar à vontade, a fim de que fosse uma experiência agradável e construtiva. Desde o começo do planejamento, não foi estipulado um número preliminar de entrevistados. Tal quantitativo seria definido pelo critério de saturação teórica, utilizada para estabelecer o tamanho final de uma amostra em estudo, interrompendo a captação de novos componentes quando as informações colhidas se repetem, e desta 
forma não tendo ganhos com o acréscimo de novos dados mediante os seguintes critérios: limites empíricos dos dados, integração dos mesmos com a teoria utilizada e sensibilidade teórica do pesquisador (DENZIN; LINCOLN, 1994; GLASER; STRAUSS, 2006).

Já a terceira etapa da coleta de dados foi a aplicação de um questionário fechado com 13 perguntas, simples e objetivas, para um conjunto maior de jovens membros da Assembleia de Deus Meritiense ${ }^{1}$. Foram aplicados 127 questionários, dos quais 100 foram considerados válidos². A maioria deles foi aplicada em um único dia, em um ensaio de um "Congresso" da mocidade, no qual estavam presentes jovens de boa parte das congregações que formam o campo da ADM. Nesse dia foram aplicados 84 questionários, sendo 72 validados. Depois, em outros eventos e encontros menores, foi aplicado o restante, até se chegar ao número de 100 questionários respondidos válidos. A amostra colhida foi do tipo não probabilística, uma amostra por conveniência, pois houve um critério de seleção não aleatório: responderam ao questionário aqueles que se dispuseram para tal. Como não havia um marco amostral da população pesquisada, ficou inviabilizada uma amostra que fosse probabilística, fato que não nos permite generalizar os resultados com precisão estatística.

\section{Um pouco do contexto das Assembleias de Deus no Brasil}

A igreja Assembleia de Deus foi fundada em 1911 em Belém do Pará, cidade na região Norte do Brasil, pelos missionários suecos Gunnar Vingren e Daniel Berg, sob o nome de "Missão de Fé apostólica". Atualmente, as Assembleias de Deus (ADs) se consolidam como a maior igreja evangélica do Brasil, e no âmbito geral só possuem um número de fiéis menor que a Igreja Católica. Segundo os censos do IBGE³ a AD possuía 2,4 milhões em 1991 e experimentou grande crescimento ao passar para 8,4 milhões em 2000. Já em 2010 foram contabilizados cerca de 12,3 milhões de assembleianos no país (cerca de 6,4\% do total da população). Desta forma,

\footnotetext{
${ }^{1}$ Nome fictício. Doravante ADM.

${ }^{2}$ Os critérios de seleção foram: estar dentro da idade estabelecida anteriormente (14-24 anos) e preenchimento adequado do questionário.

${ }^{3}$ Instituto Brasileiro de Geografia e Estatística.
} 
o seu crescimento continuou significativo, mas foi menor. Se analisada dentro do universo evangélico e pentecostal, seus números são ainda mais vigorosos: são cerca de $48 \%$ dos pentecostais e $29 \%$ dos evangélicos. Está presente em praticamente todo o território nacional, mas sua distribuição não é homogênea do ponto de vista socioeconômico e geográfico. Os assembleianos tendem a se concentrar nas camadas mais populares. Sua presença mais expressiva é nas grandes cidades, a exemplo do Rio de Janeiro, com quase 1 milhão de adeptos, e de São Paulo, com mais de 680 mil seguidores (JACOB et al., 2013). Em suma, a igreja simples que surge em uma capital afastada dos grandes centros econômicos do país fundada por missionários suecos sem grandes recursos hoje é uma das principais instituições religiosas do Brasil, mesmo que de forma diversa e fragmentada.

Assim, é fundamental pontuar que essa instituição se conforma no Brasil como uma igreja caracterizada por uma grande diversidade interna, construída desdeo seu processo deexpansãono país a partir da década de 1940 (ALENCAR, 2013; FAJARDO 2017). Tal diversidade é expressa teoricamente por Gedeon Alencar (2013) através do conceito de assembleianismos, uma construção ideal-típica que demonstra essa diversidade através de distinções de natureza sociológica (nomeadas pelo autor como assembleianismos rural, urbano, difuso e autônomo). Historicamente, ela se aprofunda com a consolidação dos chamados "Ministérios", que teriam como função atuar como um polo unificado em cada cidade, visando facilitar a atuação das igrejas locais e evitando concorrências dentro de um determinado território (CORREA, 2013). Também são conhecidas como "Igrejas-mãe" e junto com suas congregações e pontos de pregação formam um "campo" ${ }^{4}$. Contudo, esses Ministérios passaram a ter cada vez mais autonomia, e a figura do pastor-presidente adquire similaridade com a de um Bispo Católico (CORREA, 2013), criando-se um sistema de governo eclesial que mistura congregacionalismo e episcopalismo ${ }^{5}$. À medida que esses "campos" vão se desenvolvendo e expandindo sem qualquer controle externo, e lidando com realidades e públicos distintos, eles vão se diferenciando entre si.

\footnotetext{
${ }^{4}$ A expressão "Campo" aqui designa a expressão êmica para designar um conjunto de igrejas que formam o Ministério.

${ }^{5}$ Tradicionalmente as ADs não consagram formalmente bispos, mas os pastores presidentes das congregações têm, na prática, o poder equivalente ao de um bispo em igrejas episcopais.
} 
Essas observações são importantes, pois somente a partir da compreensão dessa particularidade assembleiana é possível ter a exata noção da grande complexidade de examinar a questão da identidade dos membros da $\mathrm{AD}$, que, evidentemente, apresentarão distinções entre si. Um exemplo prático dessa diversidade pode ser visto em como alguns Ministérios lidam com o "mundo": no campo estudado é permitido aos fiéis assistirem à televisão, fato que não era permitido há duas gerações, mas a $\mathrm{ADM}$, por determinação de suas lideranças, não se envolve em política. Já outros ministérios da $\mathrm{AD}$ na mesma região têm vários pastores envolvidos em eleições.

Isto posto, esclarece-se que a investigação aqui proposta não pretende dar conta de uma realidade nacional, mas apresentar algumas questões de destaque em um tipo específico de assembleianismo, marcado por um tradicionalismo no contexto interno das ADs do Brasil, mas que também apresenta tensões e influências de natureza mais urbanas/modernizantes, inseridas na Baixada Fluminense, região metropolitana do Rio de Janeiro. Particularmente, essa região se notabiliza pelo grande número de habitantes praticantes do pentecostalismo e igrejas desse tipo de religiosidade (desde as mais tradicionais como a $\mathrm{AD}$ até pequenas igrejas sem vinculações com as denominações mais conhecidas no mosaico pentecostal brasileiro), bem como a quase onipresença pública de simbologias pentecostais nos espaços públicos.

\section{Algumas palavras sobre juventude e pentecostalismo no Brasil}

Embora ainda seja majoritariamente católico, o Brasil apresenta um quadro de progressivo aumento da diversidade religiosa, fato que se reflete entre os jovens. Segundo os dados do Censo de 2010 do IBGE, dentre os brasileiros com idade entre 15 e 24 anos, cerca de $63 \%$ se declaram católicos, 21\% evangélicos (categoria que engloba protestantes históricos e pentecostais) e 10\% sem religião. Observando especificamente a juventude na Baixada Fluminense, Fernandes (2017) salienta que, ao lado do catolicismo e do pentecostalismo, o fenômeno da desvinculação religiosa tem-se mostrado bastante significativo, configurando um desafio interpretativo para a Sociologia da religião e juventude no Brasil.

Novaes (2005) pontua algumas características dos jovens pentecostais. Como regra, eles reproduzem as características socioeconômicas que a literatura aponta nesse segmento: moradores de regiões periféricas das metrópoles e espaços com forte presença migratória recente, com forte 
presença de negros e pardos, renda familiar baixa e pouca presença nas universidades. No caso dos jovens interlocutores, a partir de suas histórias familiares, foi constatado que algumas poderiam ser classificadas como de formação familiar nuclear, em que coabitam apenas os pais e seus filhos, mas também foi verificado um significativo número de famílias recombinadas, uma vez que os pais dos jovens se divorciaram, tendo se casado novamente ou não. Daqueles que estudavam no ensino médio à época da pesquisa, a grande maioria o fez em escola pública. Do ponto de vista do trânsito religioso, a maioria dos entrevistados (84\%) nasceu em lar evangélico.

Todos os pentecostais entrevistados na pesquisa afirmaram frequentar atos religiosos de sua própria crença e são os mais participantes nas atividades no interior da igreja. Quando perguntados sobre quais os valores mais importantes em uma sociedade ideal, suas respostas mais frequentes foram "temor a Deus" e "religiosidade". Também são o segmento juvenil que mais reprova o aborto e a legalização da união de pessoas do mesmo sexo (NOVAES, 2005). Essas características, em comparação com outras religiosidades juvenis, sugerem que o pentecostalismo atua como um diferencial no campo das escolhas e opiniões sobre a sociedade.

Uma das características mais significativas acerca dos jovens evangélicos apontada pela literatura é a tensão entre escolhas e práticas consideradas "mundanas" pelo discurso produzido pelas igrejas evangélicas e a efetiva experiência dos jovens, que nem sempre interpretam as mesmas práticas como problemáticas, ou, mesmo as considerando com tal, não deixam de realizá-las (SANTOS, 2008; ALVES, 2009; MESQUITA; BERTOLI, 2014). Uma das principais características do discurso pastoral das igrejas pentecostais para o seu público jovem é a prevenção contra práticas que possam ser consideradas como "pecado" ou que possam "não agradar a Deus", como sexo antes do matrimônio, uso de bebidas alcoólicas e drogas, andar com "más companhias", entre outras práticas. Em maior ou menor grau, alguns dos jovens que se afiliam às igrejas pentecostais vivenciam conflitos internos - assim como quaisquer outros indivíduos situados em condição juvenil - mas o diferencial nesse caso é que esses conflitos são em parte oriundos da tensão entre o impulso de romper com a ordem familiar acompanhado pela restrição de comportamentos dessas instituições que têm como uma de suas marcas identitárias a defesa dos valores "da família tradicional".

Um exemplo efetivo de como as igrejas pentecostais influenciam o comportamento dos jovens em relação às "coisas do mundo" é o estudo de 
Verona e Regnerus (2014), os quais salientam que essa religiosidade, a partir da promoção de normas conservadoras e sanções punitivas relacionadas ao comportamento sexual de seus jovens fiéis à iniciação sexual pré-marital dos mesmos é fortemente postergada, em comparação com jovens de outras religiosidades. Também é salientado que essas igrejas têm criado um espaço único para os seus seguidores participarem ativamente de um ambiente religioso. Desta forma, é sugerido que, no contexto socioeconômico específico, em que é marcante a atuação desse tipo de pentecostalismo tradicional, a igreja possa estar substituindo o lugar da família e da escola na comunicação sobre o comportamento sexual de adolescentes no Brasil (VERONA; REGNERUS, 2014).

No caso específico da Assembleia de Deus, é importante mencionar que, na maioria dos casos, as $\mathrm{ADs}$ trabalham com uma noção de jovem própria a essa igreja, que, embora possa estar mudando atualmente, ainda se mantinha na igreja estudada: considera-se "jovem" a moça ou o rapaz a partir dos 14 anos de idade, que permanece solteiro. Alguns podem permanecer no grupo com idade superior a 20 anos, desde que ainda não tenham se casado, desta forma utilizando-se uma noção de papel social desses indivíduos no contexto. Para esses jovens a igreja busca realizar atividades específicas.

Tradicionalmente, os membros da Assembleia de Deus são estimulados a casar cedo para evitar "tentações", ou seja, manter relações sexuais antes do matrimônio. Desta forma, tentando dar conta dos critérios objetivos e subjetivos, assim como a categoria "nativa" de juventude, optei por focar nesta pesquisa especificamente jovens solteiros entre 14 e 24 anos que participem cotidianamente das atividades da igreja. Como existem muitos critérios para se definir a noção de juventude e jovem, optou-se por esse recorte, uma vez que ele está próximo das referências internacionais, mas dialoga com a realidade específica da igreja estudada.

\section{Alguns apontamentos sobre a identidade juvenil assembleiana a partir de estudo de caso}

Aqui serão apresentados alguns dados sobre como os jovens assembleianos elaboram sua identidade, a partir da vivência na igreja, reconhecendose como assembleianos e daí elaborando sua identificação. Como dito anteriormente, o universo pesquisado é de membros regulares da ADM com 
idades entre 14 e 24 anos. Argumenta-se que tal processo de identificação possui dois marcos centrais: os "usos e costumes" e o ideal de separação com o "mundo". Tais características não representam uma novidade no âmbito da trajetória e do investimento realizado pela AD no Brasil. Todavia, elas se revelam como todo o esforço e discurso das lideranças da AD em questão, que se caracteriza como uma igreja que se coloca como tradicional no contexto dos assembleianismos - é internalizado e reelaborado pelos jovens. Para compreender um pouco desse mecanismo de identificação, foi perguntado, via questionário, a um grupo de 100 jovens da ADM: “Qual é a maior diferença da Assembleia de Deus em relação a outras igrejas evangélicas?". O resultado pode ser observado na Tabela 1.

Tabela 1 - Maior diferença ente a AD e outras igrejas evangélicas

\begin{tabular}{|c|c|}
\hline Respostas & Percentual \\
\hline Usos e costumes & $62 \%$ \\
\hline Tradição centenária da Igreja & $13 \%$ \\
\hline Fervor religioso & $22 \%$ \\
\hline Não respondeu & $03 \%$ \\
\hline
\end{tabular}

Fonte: Elaborada pelo autor.

De um modo geral, apesar dos investimentos da $\mathrm{AD}$, em especial da $\mathrm{CPAD}$, em valorizar a história da igreja como elemento identitário, parece que tal característica não tem sido reconhecida como fundamental pelos jovens. É importante salientar que, mesmo em conversas informais e formais com pastores e outras lideranças da ADM, não foi feita nenhuma menção à tradição e à história centenária da igreja, e mesmo quando estimulávamos algo do tipo, não foi obtida nenhuma menção significativa para que se pudesse fazer tal associação.

Por sua vez, a questão do fervor religioso tende a ser escolhida entre os jovens da menor faixa etária da amostra, sendo que $54,4 \%$ daqueles que assinalaram essa alternativa no questionário se encontram na faixa entre 14 e 17 anos. Já quando analisada sob a perspectiva do gênero, tal aspecto parece ser mais marcante entre as moças, uma vez que $72.5 \%$ dos jovens que a escolheram eram do sexo feminino. Essa característica assembleiana também aparece de forma bem mais consistente nos relatos, se comparada à tradição centenária da igreja. Esse "fervor" também é identificado a partir das chamadas "manifestações do espírito", ocasiões em que alguns dos chamados dons, "que são parte fundamental da teologia assembleiana" 
(FAJARDO, 2015), se manifestam. Os principais dons a serem manifestados nesses momentos de fervor, também conhecidos como "reteté", são a glossolalia e as profecias. Sabe-se que uma das principais formas de identificação é via alteridade (HALL, 2011; MOITA LOPES, 2003). Os dados analisados mostram que o fervor religioso é considerado como uma característica tipicamente assembleiana em comparação com outras igrejas evangélicas que os jovens conhecem a partir de visitas, relatos de conhecidos ou mesmo experiências familiares. A seguir alguns relatos:

Eu costumo ir na igreja na minha irmã, que é a Batista dali do outro bairro, porque às vezes tem festa ou alguma programação pra jovem aí eu vou. É muita diferença, até na hora de orar, tipo, a maioria das coisas a gente faz em pés lá eles fazem sentados. Aqui a coisa é mais quente. Fogo. Fogo pentecostal. [DINORÁ6, 17 anos].

(Ser assembleiano) é ser fervoroso, quando adoramos e louvamos a Deus não ficamos para nós mesmos, cantamos alto, adoramos mesmo, festejamos. Os outros falam para mim, nossa vocês são bem animados, eu falo é isso mesmo, nosso congresso de jovens é o melhor que tem. [VIVIANE, 18 anos].

Eu visitei uma igreja e ninguém dava glória a Deus, ninguém dava Aleluia, eu achei muito estranho porque essa igreja, eu achei estranho não tinha Grupo da Mocidade, não tem grupo das irmãs, não tem varões, achei estranho aí eu pensei: Ah, não dá não, eu não conseguiria ficar nessa igreja não, já tô com sono dentro dessa igreja. Achei este hábito bem diferente da nossa igreja. [MARIA, 15 anos].

Por sua vez, fruto de uma interpretação particular de textos bíblicos para estabelecer formas de vestimenta, comportamento e posturas, mas diferenciados de questões estritamente doutrinárias, os usos e costumes são considerados como uma das principais marcas de identificação assembleiana, de acordo com a literatura (SILVA, 2013; GANDRA, 2013). Segundo Fajardo,

\footnotetext{
${ }^{6}$ Os entrevistados possuem nomes fictícios.
} 
Usos e costumes é uma expressão nativa do campo que diz respeito principalmente à forma típica de vestimenta e de conduta exigida do assembleiano (...). Os costumes também têm uma dimensão litúrgica, referindo-se à forma como o culto assembleiano se desenvolve. Nas últimas décadas tais costumes têm sido gradualmente abolidos, embora muitos Ministérios ainda se apeguem a diversos de seus aspectos, enquanto outros os rejeitem. (FAJARDO, 2017, p.131).

Os usos e costumes também se constituem uma grande fonte de preocupação da AD como forma de controle "de autenticidade" da igreja. Como salienta Alencar (2013), embora a AD tradicionalmente não se pronuncie formalmente sobre questões teológicas, os usos e costumes já foram alvo de três importantes documentos "normativos" sobre o tema.

Vejamos então alguns dados relevantes sobre o tema no âmbito dos jovens assembleianos da ADM. Ressalta-se que a expressão "usos e costumes" é de domínio geral entre eles. Como já foi visto, segundo $62 \%$ dos jovens, essa é a maior diferença entre a AD e outras igrejas. Analisando esses dados a partir do recorte da idade, a opção por "usos e costumes" não variou significativamente, apresentando percentuais semelhantes nas três faixas etárias presentes na amostra, com o mesmo ocorrendo analisandose os mesmos dados a partir do recorte de gênero. Desta forma observa-se que é reproduzida a ideia de que os usos e costumes são um dos principais diferenciais do "ser assembleiano" no contexto do campo religioso brasileiro. Também pode-se inferir que os usos e costumes fornecem aos jovens uma noção concreta (pois é facilmente visível) de pertencimento ao tipo específico de assembleianismo construído pela ADM, na medida em que associa suas práticas às doutrinas defendidas pelos pastores e lideranças desse Ministério. Entretanto, foi verificado que nem sempre esses usos e costumes são observados na vida cotidiana desses jovens, o que pode ser interpretado, principalmente, no contexto de defesa do tradicionalismo ADM, uma falta grave, pois representa um sinal de que o "mundo está entrando na igreja".

Neste sentido, foi constatada a presença de um fenômeno nomeado por uma interlocutora "resistência silenciosa" por parte dos jovens aos usos e costumes. Desta forma, tal resistência se dá de forma discreta e velada, sem configurar um desafio aos pastores e líderes de jovens. A reação ao tradicional ocorre, ainda segundo essa jovem, num nível que não cause mal-estar e desrespeito ao pastor. 
Desta forma, percebe-se que a tensão em relação à observância das regras colocadas pelos usos e costumes é um reflexo da própria dinâmica interna presente na AD entre "modernizar sem modernidade" (ALENCAR, 2013) e aderir às práticas e regras consideradas mais "contemporâneas", expressando as próprias contradições internas típicas do conflito entre os assembleianismos. Mas, como marca identitária e expressão de uma variação tradicional dessa tipificação, mesmo as resistências são veladas, silenciosas, assim como os não cumprimentos das tradicionais regras são transformadas em categorias acusatórias: "é sempre o outro jovem que não o faz, e por isso ele "não é tão assembleiano como eu".

Assim que foi iniciado o trabalho de campo, com a ida regular aos cultos assembleianos, uma das primeiras narrativas que se destacou pela sua frequente ocorrência foi a menção aos cuidados constantes que o fiel deveria ter sobre os "perigos do mundo", o que ocorria ainda mais repetidamente nas palavras dirigidas aos jovens da igreja. Sem embargo, a "questão" do mundo como uma categoria analítica torna-se bastante complexa, na medida em que ela é, ao mesmo tempo, uma construção teológica, sociológica e êmica.

O tipo ideal elaborado por Weber (2000) de "mundo" define, em termos sociológicos, os limites do "mundo" como relações sociais que afastam as pessoas do "divino", que é colocado a partir do momento em que as mesmas relações afastam o religioso do empenho de sua salvação individual. Isso vai ao encontro da ênfase encontrada no discurso assembleiano e nos relatos colhidos na questão das escolhas individuais, que são entendidas como fundamentais no processo de "salvação", mas também como marcos definidores da identidade juvenil assembleiana: o jovem assembleiano é "separado" (do mundo). Em geral, observei que a AD reforça a necessidade e a importância de que os jovens se mantenham separados do "mundo" visando a sua salvação individual, mantendo uma atitude condizente com os princípios de conduta que são esperados e cobrados por parte da igreja, na figura de líderes, pastores e membros destacadamente tidos como exemplos de virtude e retidão. Com isso, a ênfase da igreja não é na manutenção das virtudes como mecanismo de reforço da identidade assembleiana, mas para que os jovens consigam se manter "nos caminhos do senhor" e, desta forma, conquistar sua salvação.

Isto posto, argumento que a rejeição ao mundo e a busca por tal salvação tem como consequência, talvez não intencional, forjar um marco definidor da identidade juvenil, mediante o contraste com o "jovem do mundo". É 
relevante também destacar o papel estratégico que a figura do "demônio" tem nas narrativas produzidas pelos pregadores assembleianos no contexto pesquisado. Neste sentido, na medida em que tal figura é descrita nas narrativas bíblicas como o "príncipe do mundo", ele se presta a reforçar a dimensão simbólica do "mundo" como um espaço oposto àquele que deve ser ocupado pelo "crente". Muitas falas registradas são bastante significativas, pois representam bem como os jovens internalizam e reelaboram a tensão com o mundo tal como citado nas falas da igreja, como as que podem ser vistas a seguir:

No mundo são muitos pratos oferecidos, né? Os jovens têm a mente distorcida em relação a relacionamento. Hoje eles só querem saber de ficar, terem relacionamento fora do casamento, curtir, beber, o jovem cristão não já sabe que aquilo dali não é lícito para ele, não lhe convém (ou seja) isso para mim é lícito, né? Mas não me convém. Eu sei que é que aquilo ali vai gerar um coisa ruim lá na frente, então aquilo ali vai empatar minha vida. [VERA 7,22 anos].

Existem na Bíblia algumas passagens que falam do mundo sobre bebidas alcoólicas, pecado, matar, roubar, se prostituir, são pecados, mentira é pecado. Então as pessoas do mundo que não conseguem entender a Bíblia, o que é pecado. Pecado para nós é aquilo que a Bíblia relata. É o que eu disse, são aprendizados do jovem cristão. Nós, cristãos, aprendemos assim o que é pecado, o que é certo e o errado. Então o mundo são aquelas pessoas, não de uma forma geral, porque existem pessoas que não estão dentro da igreja que não fazem coisas erradas, e não é considerado apenas que faz coisas certas no mundo é que está fora da igreja. [CRISTIANO, 17 anos].

Fomos chamados para ser separados, de ser o exemplo. Assim... as coisas do mundo, são boas? São. Só que nós buscamos algo muito melhor, então o que a gente encontrar aqui, o que a gente tiver não se compara à glória que nós vamos receber a tudo o que vamos ter se nós formos corretos, se formos fiéis àquilo tudo o que nós colocamos no nosso coração, aquele propósito que nós temos, então eu acho que não vale a pena se sujar com as coisas do mundo. [KELLY, 20 anos].

\footnotetext{
${ }^{7}$ Os nomes dos informantes são fictícios.
} 
A representação de "mundo" elaborada pelos jovens revela que o mesmo é percebido como algo que "suja" a pessoa, e ainda visto como um lugar que oferece coisas "boas", que deve ser rejeitado. Eles também resumem bem a visão do "mundo" como um local onde há corrupção, pois nele não há a presença de comportamentos que se baseiam nos "padrões bíblicos". Como já foi salientado, a renúncia aos prazeres que o "mundo oferece" às pessoas, principalmente aos jovens, é uma das condições para a salvação, e, por isso, indispensável àqueles que criam laços de pertencimento e reconhecimento desse grupo identitário. Elas também demonstram que alguns dos jovens têm um bom conhecimento de algumas passagens bíblicas que trazem a questão do mundo como um local de onde o jovem deve ser manter "separado", embora tenha que conviver nele.

Também foram registrados durante a pesquisa vários relatos e mensagens que a reforçam, no contexto da internet e das redes sociais, que, por sua vez, são um "espaço do mundo". Mas deve-se lembrar que, mesmo quando o jovem está nesses espaços, ele "deve" levar consigo marcas e símbolos de tal separação, de tal forma que essa característica também acaba por demarcar a identificação juvenil assembleiana nesses locais. Foi observado que a maior dificuldade apontada pelos nossos interlocutores é a questão de ter que renunciar aos prazeres e tentações do mundo, o que implica ter maiores dificuldades e mais desafios diante do "jovem do mundo". Destaca-se também a noção de propósito como chave para o entendimento do esforço do jovem: o propósito é uma espécie de compromisso assumido no qual ele se coloca como sendo "separado" do mundo para "estar junto com Deus", e para tal esforça-se no sentido de seguir uma vida guiada nesse compromisso e nas regras estabelecidas para tal. As principais "regras", que devem ser entendidas como códigos culturais, são: não fazer sexo antes do casamento; não consumir álcool, cigarro e drogas ilícitas; ter comportamento considerado "digno" em todos os espaços sociais. Também há algumas formas de propósitos mais específicos, que se assemelham como "votos", como fazer uma promessa para uma finalidade específica, também algo comum na prática espiritual dos jovens. Desta forma, a noção de "propósito" materializa e dá sentido concreto na questão da tensão com o mundo, uma vez que ceder às suas tentações representaria uma falha nesse compromisso. 


\section{Palavras Finais}

Conclui-se o presente texto apontando para uma definição instrumental da formulação de identidade juvenil assembleiana. Assim, ela pode ser definida como uma forma peculiar de identidade, elaborada a partir da diferenciação dada na interação com outras identidades e conjunturas percebidas ou vivenciadas, e reivindicando características marcantes dos assembleianismos, especialmente o ideal de separação com o "mundo" e a prática reapropriada dos "usos e costumes" assembleianos, apoiadas em um senso de comunidade gerado a partir do sentimento de pertencimento a uma forma singular de religiosidade congregacional, conformando um habitus (BOURDIEU, 2011) específico. Contudo, é preciso salientar que tal definição só pode ser considerada mais profícua no contexto do assembleianismo específico estudado. Como toda identidade socialmente construída, a identidade juvenil assembleiana é elaborada na interação e a partir da diferenciação com outras formas de identidades e representações.

Uma última questão é pensar em que medida a identidade juvenil assembleiana se diferencia de outros padrões de identidades. Para tal, minha chave explicativa reside na ideia de que tal identidade se configura como um tipo de resistência, ainda que sujeita a transformações, às novas formas de identificações não estáveis, que são marcantes na contemporaneidade, descritas por Hall, fenômeno que Hervieu-Léger e Novaes identificam no campo religioso. Assim indago em que medida essa formulação se ajusta com que vimos na identidade juvenil assembleiana? Diante dos dados colhidos, parece-nos que muito pouco. Em situações muito específicas, segundo relatos, o jovem pode vir a, por exemplo, utilizar-se da estratégia de negar ou, ao menos, atenuar sua identificação com a igreja, visando a uma nova interação momentânea ou escapar de uma situação de preconceito. Mas não vimos casos em que uma outra identificação pudesse ver evocada em outro momento ou conjugada. Em suma, os jovens assembleianos pesquisados não podem ser alocados como aderentes à identidade "pós-moderna". Ao contrário, se afirmam enquanto tal negando a duplicidade de identificação, e, em geral, a exteriorizando em todos os espaços sociais onde eles circulam, na medida do possível.

Para Hervieu-Léger, a identidadereligiosa contemporânea nãoéherdada, mas uma construção individual "a partir dos diversos recursos simbólicos colocados à sua disposição" (HERVIEU-LÉGER, 2008, p. 64). Comparando esse quadro com o contexto da identidade juvenil assembleiana, verifica-se 
muito pouco em comum. Diante dos dados colhidos, não temos elementos que permitam inferir alguma similaridade relevante. Em primeiro lugar, no contexto dos jovens da ADM, a maioria das identidades religiosas são herdadas, na medida em que nada menos que $84 \%$ dos jovens da base da amostra quantitativa afirmaram nascer em lar evangélico. Assim, ao menos no âmbito da ADM, não há sinais de crise na transmissão religiosa familiar. Tampouco foi verificada alguma característica de bricolagem nas práticas de fé no plano dos jovens assembleianos. Como visto, uma das principais marcas distintivas da igreja é a afirmação da tradição e da manutenção das doutrinas consagradas por décadas na igreja, diante da concorrência das outras denominações. Eventualmente, alguma forma de bricolagem pode vir a ocorrer em um tipo de assembleianismo autônomo, mas seria uma exceção à regra do padrão doutrinário conservador assembleiano.

\section{Referências}

ALENCAR, Gedeon.

(2013). Matriz Pentecostal Brasileira: Assembleias de Deus 1911-2011. Rio de Janeiro, Novos Diálogos.

ALVES, Maria de Fátima.

(2009). Um/uma jovem separado/a do mundo: igreja, juventude e sexualidade na perspectiva de jovens da Assembleia de Deus em Recife $P E$. Tese apresentada à Universidade Federal de Pernambuco (UFPE).

BAUMAN, Zygmunt.

(2003). Amor Líquido: sobre a fragilidade dos laços humanos. Rio de Janeiro, Zahar.

BOURDIEU, Pierre.

(2011). A economia das trocas simbólicas. São Paulo, Perspectiva.

CORREA, Marina.

(2013). Assembleia de Deus: ministérios, carisma e exercício de poder. São Paulo, Fonte Editorial.

DENZIN, Norman; LINCOLN, Yvonna (eds). (1994). Handbook of qualitative research. Thousand Oaks, Sage Publications.
FAJARD0, Maxwell.

(2017). "Onde a luta se travar": uma história das Assembleias de Deus no Brasil. Curitiba, Prismas.

FERNANDES, Sílvia.

(2017). Desvinculação religiosa entre os jovens é maior do que a adesão ao pentecostalismo. Disponivel em: <http://www.ihu.unisinos. br/566480-a-ascensao-da-culturapentecostal-nas-periferias-brasileiras-ea-influencia-dos-evangelicos-na-politica>. Acesso em 01 de setembro de 2018.

GANDRA, Valdinei.

(2013). Patrimônio cultural da Assembleia de Deus: memória e identidade na criação do centro de estudos do movimento pentecostal - CEMP. Dissertação de Mestrado apresentada a Universidade da Região de Joinville.

GLASER, Barney; STRAUSS Anselm.

(2006). The discovery of grounded theory: strategies for qualitative research. New York, Aldine de Gruyter.

HALL, Stuart.

(2011). A identidade cultural na pósmodernidade. Rio de Janeiro, DP\&A. 
HERVIEU-LÉGER, Danièle.

(2008). O Peregrino e o convertido: a religião em movimento. Petrópolis, Vozes.

JACOB, Cesar et al.

(2013). Religião e território no Brasil: 1991/2010. Rio de Janeiro, Ed. PUC-Rio.

KAUFMANN, Jean-Claude.

(2013). A entrevista compreensiva: uma guia para pesquisa de campo. Petrópolis, Vozes / Maceió, Edufal.

MAGALHÃES, Alexander.

(2016). Amigo de fé: estudo sobre religião e amizade entre jovens assembleianos na Baixada Fluminense. Tese apresentada à Universidade do Estado do Rio de Janeiro (UERJ).

MARIZ, Cecília.

(1994). Coping with poverty: Pentecostals and Christians base communities in Brazil. Philadelphia, Temple University.

MESQUITA, Wânia; BERTOLI, Naiana.

(2014). Jovens evangélicos moradores de favelas: algumas expressões de sua sociabilidade na cidade de Campos dos Goytacazes RJ. (Syn)Thesis, v. 7, p. 63-74.

MOITA LOPES, Luiz Paulo. (0rg.)

(2003). Discursos de identidades: discurso como espaço de construção de gênero, sexualidade, raça, idade e profissão na escola e na família. Campinas, Mercado das Letras.
NOVAES, Regina.

(2005). Juventude, percepções e comportamentos: a religião faz diferença? In: ABRAM0, Helena; BRANC0, Pedro. Retratos da juventude brasileira: análises de uma pesquisa nacional. São Paulo, Fundação Perseu Abramo / Instituto Cidadania.

SILVA, Cláudio José.

(2003). A Doutrina dos Usos e Costumes da Assembleia de Deus. Dissertação de Mestrado apresentada à Pontifícia Universidade Católica de Goiás.

SANTOS, Maria Goreth.

(2008). "Todas as coisas me são lícitas, mas nem todas me convêm": Representações sobre sexualidade entre solteiros evangélicos. Tese apresentada à Universidade do Estado do Rio de Janeiro (UERJ).

VERONA, Ana Paula; REGNERUS, Mark.

(2014). Pentecostalism and premarital sexual initiation in Brazil. Revista brasileira de estudos da população, São Paulo, v. 31, n. 1, p. 99-115.

WEBER, Max.

(2000). Economia e Sociedade: fundamentos da Sociologia compreensiva. vol. 1. Brasília, Editora UNB.

\section{Recebido em}

abril de 2018

\section{Aprovado em}

agosto de 2018 